ANA LUIZA TESSER ARGUELLO

A Cláusula Penal nos Contratos Empresariais

\author{
Dissertação de Mestrado
}

Orientadora Professora Dra. Juliana Krueger Pela

UNIVERSIDADE DE SÃO PAULO

FACULADE DE DIREITO

São Paulo - SP 
ANA LUIZA TESSER ARGUELLO

\title{
A Cláusula Penal nos Contratos Empresariais
}

Tese apresentada a Banca Examinadora do Programa de Pósgraduação em Direito, da Faculdade de Direito da Universidade de São Paulo, como exigência parcial para obtenção do titulo de Mestre em Direito, na área de concentração de Direito Comercial, sob a orientação da Prof(a) Doutora Juliana Krueger Pela.

\section{UNIVERSIDADE DE SÃO PAULO}

\section{FACULADE DE DIREITO}

\author{
São Paulo - SP
}




\section{RESUMO}

Ana Luiza Tesser Arguello. A Cláusula Penal nos Contratos Empresariais. Dissertação de Mestrado. Faculdade de Direito, Universidade de São Paulo, 2018.

A presente dissertação de mestrado teve como objeto o estudo da cláusula penal nos contratos empresariais. Nesse trabalho, analisa-se, primeiramente, as discussões existentes na doutrina especializada quanto à função da cláusula penal e, em decorrência, a existência de diversas modalidades de cláusulas inseridas dentro de um mesmo chapéu que se chama de cláusula penal. Eleitas duas modalidades da figura para o estudo, cláusula penal substitutiva e cumulativa, empreender-se-á uma análise do papel da cláusula penal na alocação de riscos nos contratos empresariais, ilustrando-se essa questão com discussões que circundam a denominada teoria do efficient breach, arraigada no direito estadunidense, mas que no Brasil não de dispendem muitos estudos. Ao fim, apontar-se-á a constatação de que o papel da cláusula penal na alocação dos riscos contratuais é muito limitado pelo atual regramento da figura pelo Código Civil e, talvez em razão disso, há um descasamento entre o dever ser e a utilização da figura na prática comercial.

Palavras-chave: cláusula penal, contratos empresariais. 


\begin{abstract}
Ana Luiza Tesser Arguello. Penalty Clause in Commercial Contracts. Master Thesis. Faculty of Law, University of São Paulo, São Paulo, 2017.

The purpose of this dissertation was to study the penalty clause in commercial contracts. We first analyze the discussions in the specialized doctrine regarding the purpose of the penalty clause and, therefore, the existence of several modalities of clauses that are called by penalty clause. Having chosen two modalities of the figure for the study, the substitutive and the cumulative penalty clause, an analysis of the role of the penalty clause in the allocation of risks in commercial contracts will be undertaken, illustrating this matter with discussions surrounding the so-called efficient breach theory. Finally, it will be pointed out that the role of the penalty clause in the allocation of contractual risks is very limited by the current regulation of the figure by the Civil Code and, perhaps because of this, there is a mismatch between the law and the practical use of the penalty clause in commercial practice.
\end{abstract}

Key words: penalty clause, commercial contracts. 


\section{SUMÁRIO}

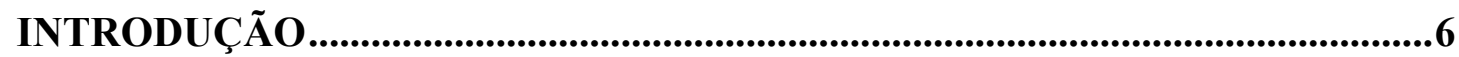

CAPÍTULO 1. CLÁUSULA PENAL: PANORAMA ATUAL E DISCUSSÕES

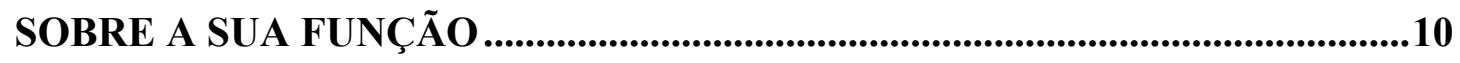

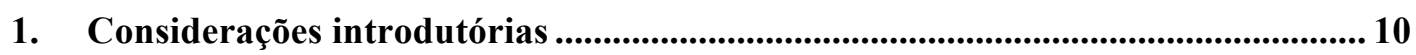

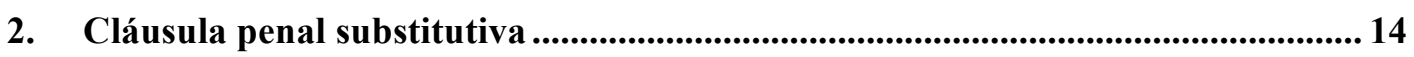

2.1. Cláusula penal de função mista como a visão tradicional .................................. 15

2.2. Tentativa de superação da visão tradicional: a proposição de uma cláusula "precipuamente punitiva" (a "cláusula penal propriamente dita") ………………............ 19

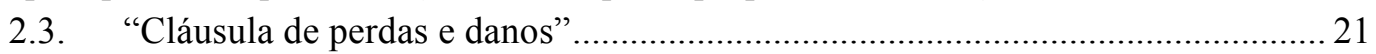

2.3.1. Distinção entre penalty clause e liquidated damages clause no common law 23

3. Cláusula penal cumulativa 24

3.1. Argumentos contrários à aceitação da uma cláusula penal cumulativa: a questão

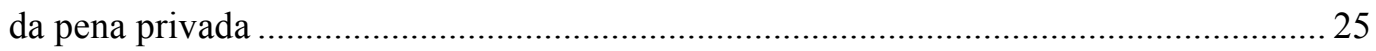

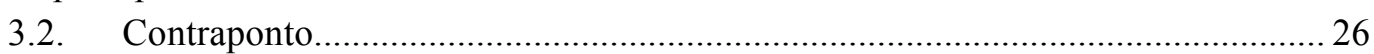

4. Conclusão: duas modalidades de cláusula penal ........................................................ 32

CAPÍTULO 2. CLÁUSULA PENAL NOS CONTRATOS EMPRESARIAIS....34

1. Observação metodológica...................................................................................................34

2. O que se entende por contratos empresariais..............................................................36

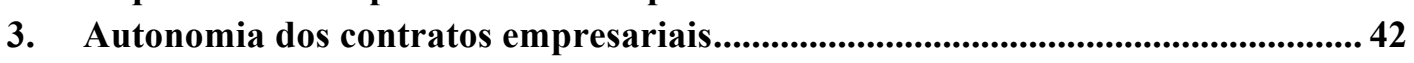

4. Alocação dos riscos nos contratos empresariais e cláusula penal............................45

5. Alocação de risco diversa para cada modalidade de cláusula penal (cumulativa e

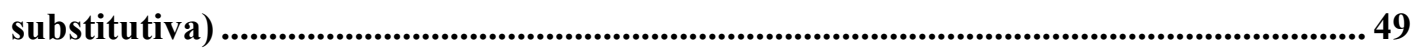

5.1. Cláusula penal cumulativa: reforço ao vínculo obrigacional.............................. 49

5.2. Cláusula penal substitutiva: previsibilidade às contratações .............................. 50

5.2.1. Alocação dos riscos decorrentes da liquidação dos danos............................... 50

5.2.2. Reforço da obrigação ou limitação de responsabilidade: consequências levadas

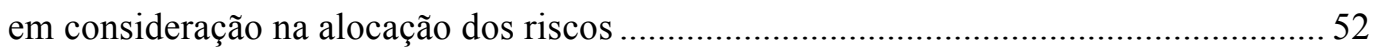

5.2.3. Cláusula penal em favor do devedor........................................................... 53

5.2.4. Possibilidade de liquidação dos danos suplementares e suas implicações para a

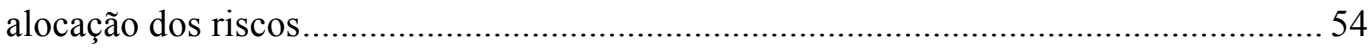

6. Teoria do efficient breach e cláusula penal .................................................................55

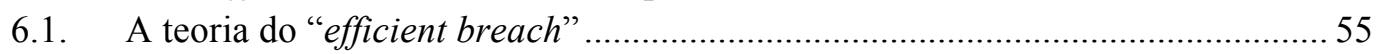

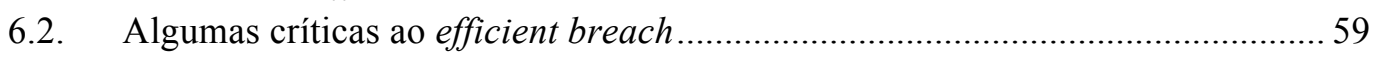

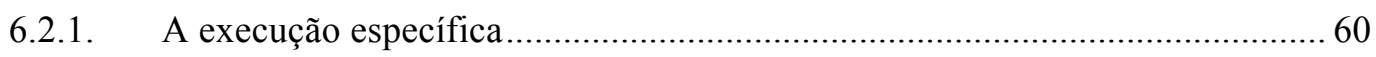

6.2.2. As partes contratam para que o contrato seja cumprido .................................. 62

6.2.3. O direito deve privilegiar o contratante diligente e probo ............................... 62

6.2.4. O direito não deve tutelar o comportamento oportunista e a boa-fé objetiva... 64

6.2.5. Eficiência do sistema contratual como um todo e o sistema reputacional....... 67

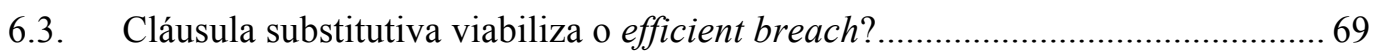

6.4. Outro lado: ilustração quanto à importância do reforço do vínculo obrigacional 75 
CAPÍTULO 3. CLÁUSULA PENAL NO CÓdIGO CIVIL..................................79

1. Interpretação das regras do Código Civil aos contratos empresariais ................. 79

2. A cláusula penal prevista no Código Civil...........................................................82

3. Limite da cláusula ao valor da obrigação principal: consequências para a interpretação da função da cláusula penal no direito brasileiro e restrição às

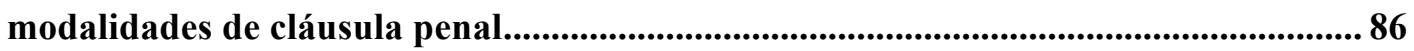

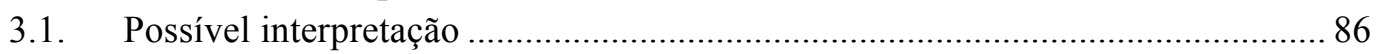

3.2. Dificuldade interpretativa em contratos de colaboração...................................... 88

3.3. Limitação às diferentes modalidades de cláusula penal ..................................... 91

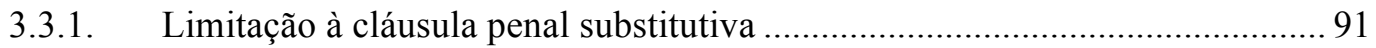

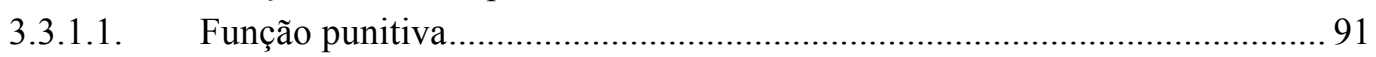

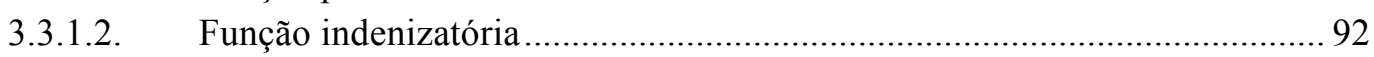

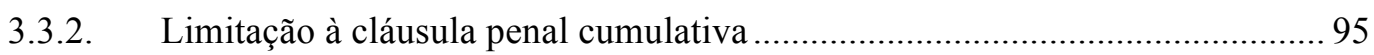

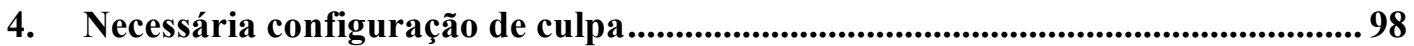

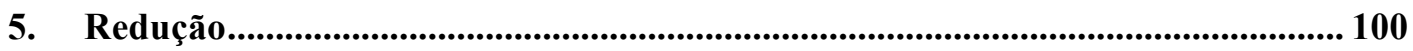

5.1. Redução equitativa por cumprimento parcial .................................................. 101

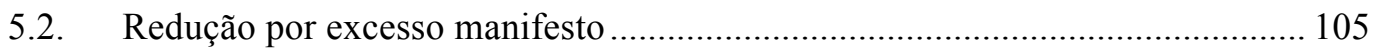

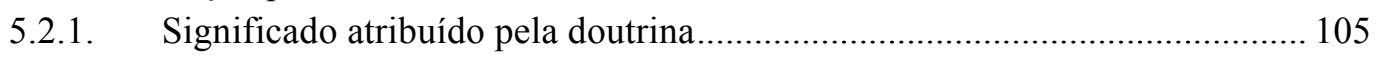

5.2.2. Interpretação dessa regra aos contratos empresariais ................................... 106

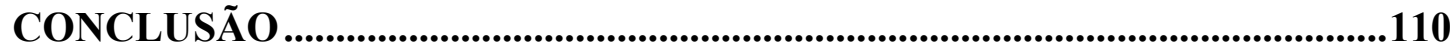

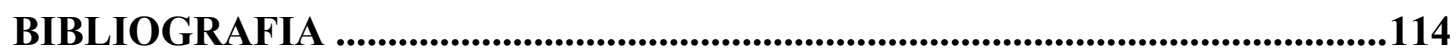

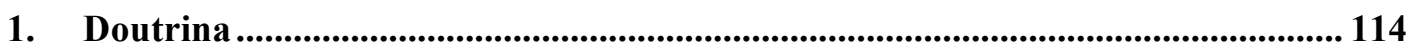

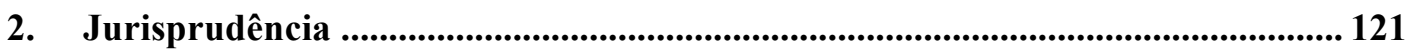




\section{INTRODUÇÃO}

A despeito de uma evolução no estudo de uma teoria geral dos contratos empresariais no direito brasileiro ${ }^{1}$, ainda há pouco, ou nenhum, estudo sobre diversos aspectos da teoria geral desses contratos, como, por exemplo, o estudo da cláusula penal sob a ótica própria dos contratos empresariais ${ }^{2}$. A carência de estudos específicos sobre o tema parece contradizer com o fato de que a cláusula penal é estipulação muito frequente na prática empresarial.

A pesquisa tem por objeto o estudo da aplicação da cláusula penal nos contratos empresariais. Parte-se da hipótese ${ }^{3}$ de que o regramento da cláusula penal no Código Civil é inadequado aos contratos empresariais para desenvolver um estudo sobre a cláusula penal nesses contratos.

\footnotetext{
${ }^{1}$ Citem-se, por exemplo, Paula Forgioni, Contratos Empresariais - Teoria Geral e aplicação, $2^{\mathrm{a}}$ ed., São Paulo, Revista dos Tribunais, 2016 e Wanderley Fernandes (coord.), Contratos Empresariais Fundamentos e Princípios dos Contratos Empresariais, São Paulo, Saraiva, 2007 (série GV Law).

${ }^{2}$ A esse respeito, algumas obras consultadas dedicam-se em tópicos específicos ao estudo da cláusula penal nos contratos comerciais ou no direito comercial. Mucio Continentino, por exemplo, trata da cláusula penal sob um aspecto mais amplo do direito comercial, com o fim de entender a cláusula penal no contexto da incidência do devedor em mora em casos de falência (Da Clausula Penal no Direito Brasileiro, São Paulo, Saraiva \& Cia., 1926, p. 141-147). No direito argentino, por sua vez, Aída Kemelejar de Carlucci trata da cláusula penal em tipos contratuais de direito comercial, distinguindo regras específicas para cada tipo, mas sem se preocupar com a aplicação genérica da figura nessas contratações, uma verdadeira teoria geral (La Clausula Penal, Buenos Aires, Depalma, 1981). Não foi encontrado, porém, obra que trate especificamente da cláusula penal nos contratos empresariais, e não no direito comercial em geral, como propõe Mucio Continentino, e nem em contratos específicos, como propõe Carlucci, sem propor uma teoria geral e abstrata sobre o assunto.

${ }^{3}$ Conforme ensina Julia Maurmann Ximenes, o problema de pesquisa deve ser sempre colocado de forma interrogativa e sua definição sofrerá influências das experiências do pesquisador e do seu senso comum, que será modificado a partir do conjunto de conhecimentos utilizados como quadro de referência. Aponta que o processo de construção do conhecimento científico pode ser encarado a partir do tripé problema-hipótese-marco teórico. E que para "'construir' o caráter científico do tema" devese partir da "definição de uma pergunta que inclua conceitos relacionados entre si e que, após a pesquisa propriamente dita, possa comprovar ou não a hipótese levantada". A partir do problema, deve ser definida a hipótese, que "diferentemente do que o senso comum costuma imaginar, não é uma pergunta. Ao revés, é uma solução prévia dada pelo pesquisador. O fato pode parecer estranho aos que não são familiarizados com a atividade de pesquisa. Para quê proponho um problema se já possuo a resposta? Os que pensam assim, desconhecem a provisoriedade da hipótese. A prática científica busca acabar, pelo menos por determinado período de tempo, até que outras investigações demonstrem o contrário, com a precariedade da resposta adotada. Isso porque a hipótese outra coisa não é senão a solução prévia ao problema, passível de ser confirmada ou não. Portanto, a atividade de pesquisa é a busca da confirmação ou rejeição da hipótese elaborada". (O processo de produção científico jurídica - O problema é o problema, Anais do XVII Congresso Nacional do COPENDI, Florianópolis, Fundação Boiteux, 2008, p. 4798).
} 
Levando em consideração as dificuldades interpretativas relacionadas à função da cláusula penal na literatura civilista sobre o tema, propõe-se um estudo que analisa a cláusula penal sob a ótica empresarial, pautando-se pela medida em que a cláusula penal atua na alocação dos riscos dos contratos empresariais. Essa lógica, aliada à interpretação específica que merece ser dada a esses contratos, servirá a ilustrar que o regramento atual sobre cláusula penal não é adequado para regular as diferentes alocações de risco propostas pela figura, em suas duas modalidades possíveis (substitutiva e cumulativa).

Parece haver um descasamento entre a prática comercial e a vontade das partes com a regulação do tema, o que traz dificuldades interpretativas e inconsistências na aplicação da cláusula penal. É esse descasamento que se pretende analisar.

Algumas limitações ao tema são importantes nessa introdução. Não se propõe detalhar o regime jurídico da cláusula penal, mas estuda-la, sob o aspecto da sua função na alocação dos riscos nos contratos empresariais. Não se propõe uma análise histórica ou comparada da figura, mas a sua análise no direito brasileiro e no direito atual. Notícias históricas e de direito estrangeiro são feitas apenas para ilustrar determinado ponto de pesquisa. Não se pretende analisar contratos em geral, mas apenas aqueles empresariais, ainda que algumas considerações feitas nesse estudo possam ser extensíveis a outras modalidades de contratação.

Estudar a utilização dessa figura tradicional de direito civil na lógica própria dos contratos empresariais contribui para a sua consagração no panorama científico do Direito Comercial, pois ao tempo que reforça o peso da tradição dos estudos da dogmática jurídica, inexoravelmente prestigiados por um estudo civilista, oxigena a dogmática comercialista com as considerações que o tema enseja no campo da ciência econômica e da visão pragmática dada ao direito.

Nessa linha, a dissertação está dividida em três capítulos. No primeiro, procura-se evidenciar as discussões existentes na doutrina sobre a função da cláusula penal e, em decorrência, a existência de diversas modalidades de cláusulas inseridas dentro de um mesmo chapéu que é um conceito único de cláusula penal. Essa situação 
traz incoerências, e exige que se delimite exatamente o que se entende por cada modalidade e quais delas são efetivamente penais. Delimita-se, então, duas modalidades de cláusula penal, as substitutivas e as cumulativas, que pautarão o estudo dali para frente.

No segundo capítulo, procura-se apontar a adequação da cláusula penal, nas modalidades substitutiva e cumulativa, para os contratos empresariais e como elas funcionam como instrumento de alocação de risco nessas contratações. Alude-se, nesse momento do estudo, à teoria do efficient breach, arraigada no direito estadunidense, mas que no Brasil é pouco desenvolvida. Sem intenções de defender ou não a aplicação dessa teoria ao direito brasileiro, o seu estudo pode ser de grande valia para ilustrar as funções exercidas pela cláusula penal e de como ela deve ser enxergada como instrumento na alocação dos riscos contratuais.

No terceiro e último capítulo, evidencia-se que o papel exercido pela cláusula penal na alocação dos riscos nos contratos empresariais é limitado pelo atual regramento da figura pelo Código Civil e que, talvez em razão disso, há um descasamento entre o dever ser e a utilização da figura na prática comercial.

Ainda, faz-se duas considerações terminológicas. Como se verá, são utilizados os termos credor e devedor para designar a parte que tem direito à cláusula penal e a parte que inadimpliu e deve arcar com ela. Tais termos são utilizados de maneira ilustrativa, ainda que, a depender do caso, não tenham relação direta com a posição de credor e devedor na relação contratual em que inserida a cláusula penal, mas apenas à obrigação a ela relacionada. Isso porque, em relações contratuais complexas, frequentes na prática comercial, há obrigações recíprocas e ambas as partes figuram como credores e devedores de determinadas prestações, dificultando uma distinção entre esses dois polos ${ }^{4}$.

\footnotetext{
${ }^{4}$ A esse respeito, sobre distinguir a posição de credor e devedor em relações obrigacionais, observa Judith Martins-Costa que "não se trata, obviamente, de uma noção equivocada. Indiscutivelmente há, em toda a relação obrigacional, a criação de um vínculo jurídico ligando credor e devedor e há, igualmente, o nascimento de direitos subjetivos de crédito e de deveres jurídicos (dívida). Porém, não sendo de modo algum incorreta, essa é, porém, uma noção insuficiente para dar contra de algumas manifestações do fenômeno obrigacional. É que a relação obrigacional pode ser uma (simples) ou múltipla (complexa). No primeiro sentido, significa a existência de um só crédito e a sua respectiva dívida. Na segunda opção, representa um conjunto de vínculos emergentes de um mesmo fato jurídico" (A Boa-Dé no Direito Privado: critérios para a sua aplicação, São Paulo, Marcial Pons, 2015, p. 200).
} 
A outra consideração terminológica diz respeito à cláusula penal. Quando se fala em cláusula penal (independentemente da modalidade escolhida) trata-se da verdadeira cláusula, como previsão contratual específica. A prestação estipulada na cláusula penal (normalmente de cunho pecuniário, mas não obrigatoriamente) será denominada multa. A utilização do termo multa (e não "pena" ou "penal convencional", como é feito por muitos autores) se deve em razão da multa poder ser tanto indenizatória quanto punitiva, podendo ser utilizada em qualquer modalidade de cláusula penal. Além disso, o termo "multa", ainda que possa não ser o mais técnico possível, aproxima-se do termo utilizado na prática comercial. Diante dessas ressalvas, parece ser o termo mais adequado. 


\section{CONCLUSÃo}

Ao longo deste trabalho foram tecidas conclusões parciais a respeito dos principais assuntos estudados, que aqui são apontadas de forma consolidada:

1. Da análise da doutrina civilista é possível se concluir que, ao fim e ao cabo, há duas modalidades de cláusula penal, aquela substitutiva, e aquela cumulativa.

a. A cláusula substitutiva é aquela que substitui a indenização. No caso de inadimplemento, o credor tem uma alternativa, podendo pleitear $o$ cumprimento da prestação devida ou a cláusula penal. A cláusula penal é devida no lugar da indenização. A sua incidência ocorre, porém, independentemente dos danos: não há necessidade de comprová-los para exigir a multa e, ainda que se comprove a sua inexistência, a multa ainda é devida. É a cláusula penal tradicional, havendo quem diga que exerce caráter mais indenizatório ou mais punitivo. Prevalece a sua natureza mista, um híbrido de pena e indenização. Sua função poderá ser averiguada apenas no momento do inadimplemento, a depender do montante dos danos no caso em concreto: se inferior à multa, atua como pena; se igual à multa, atua como indenização pelo montante integral; se inferior à multa, atua como indenizatório, mas limitando a responsabilidade.

b. A cláusula cumulativa soma-se à eventual indenização devida e tem função apenas punitiva, e não indenizatória. Reflete o exercício da função punitiva por excelência, atuando desde o momento da celebração do contrato. A doutrina é receosa ao aceitar essa figura, sob o fundamento principal de que seria uma pena privada que é repelida pelo ordenamento. Esse preconceito deve ser superado. De um lado porque a função punitiva está presente também na cláusula substitutiva e pode se manifestar, no caso em concreto, no mesmo montante e intensidade que na cláusula penal cumulativa. De outro, porque há outras figuras no ordenamento jurídico brasileiro que funcionam como verdadeiras penas privadas (cominações impostas sobre um particular, 
sem qualquer substrato indenizatório, em benefício de outro particular) e que são amplamente aceitas.

2. A cláusula penal é importante instrumento de alocação dos riscos nos contratos empresariais.

a. Cláusula substitutiva traz previsibilidade às contratações, por ser um montante fixo devido em caso de inadimplemento. Ela aloca os riscos decorrentes da liquidação dos danos, que podem ser de difícil valoração pecuniária e de difícil comprovação. As funções de reforço da obrigação ou de limitação da responsabilidade, porém, não são por excelência da cláusula penal substitutiva, pois são apenas consequências verificáveis a posteriori e dependentes do valor do dano no caso de inadimplemento, o que é incerto no momento da contratação (ainda que haja algum grau de certeza). Ao trazer previsibilidade à contratação, pode ser meio de desvinculação do devedor quando o credor não puder se valer da execução específica. Esse risco é alocado pelas partes no momento da contratação, ao precificar um montante invariável devido pelo inadimplemento.

b. A cláusula cumulativa atua como instrumento de reforço ao vínculo obrigacional. Pode ser um instrumento apto a viabilizar a contratação de partes desconhecidas, por aumentar a confiança, objetivamente considerada, de que o contrato será efetivamente cumprido. Essa função pode também ser exercida pela cláusula penal substitutiva, mas há maior incerteza sobre esse aspecto, sendo adequada, portanto, a ideia de cláusula penal cumulativa.

3. As regras previstas no Código Civil devem ser interpretadas à luz da lógica própria dos contratos empresariais.

a. Crítica à previsão que limita o valor da multa prevista na cláusula penal àquele da obrigação principal. Observa-se um descasamento entre o dever ser, inscrito nas regras que regulam a cláusula penal do 
Código Civil e a prática empresarial. Esse descasamento é prejudicial, podendo inviabilizar determinadas contratações, ao aumentar o grau de incerteza e insegurança. Por ser uma regra de cunho proibitivo, é difícil defender que poderia ser afastada de plano a sua incidência aos contratos empresariais, devendo-se procurar o real valor da obrigação principal no caso em concreto.

i. Há uma dificuldade interpretativa de se identificar a obrigação principal em contratos de colaboração, bem como de valorá-la. Aplicação dificultada sobremaneira nos contratos de colaboração, nos quais o negócio é visto como um processo, ao longo do qual muitas prestações e contraprestações não encontram contrapartidas facilmente identificáveis, mas são uma miríade de obrigações explícitas e implícitas que nem sempre se contrapõem e se equivalem.

ii. Há uma limitação à cláusula penal substitutiva e à sua função de trazer previsibilidade às contratações, seja no seu aspecto punitivo, seja no seu aspecto indenizatório (o valor da obrigação inadimplida não significa necessariamente o valor dos danos).

iii. Ainda que não proíba de plano o exercício de uma função punitiva, própria das cláusulas substitutivas, acaba por inviabilizar em muito que essa cláusula seja estipulada na prática.

b. Possibilidade de se flexibilizar algumas regras, tendo em vista a lógica própria dos contratos empresariais. É importante viabilizar às partes a alocação de riscos de acordo com a preferência dos agentes econômicos e da operação econômica em questão.

i. Possibilidade de incidir cláusula penal independentemente de culpa, afastando-se, se as partes assim preverem, a incidência 
desde que haja descumprimento culposo da obrigação. Afastar a incidência de culpa não parece contrária ao ordenamento, que permite a responsabilização por caso fortuito e força maior independentemente de culpa se as partes assim o quiserem.

ii. A regra de redução proporcional (primeira parte do artigo 413 do Código Civil) deve ser aplacada equitativamente e com vistas aos aspectos objetivos da operação econômica subjacente ao contrato, bem como à luz dos riscos alocados pelas partes no programa contratual. É regra que pode ser flexibilizada de acordo com as partes, e mesmo afastada.

iii. Não parece ser condizente com a lógica dos contratos empresariais a autorização de redução da cláusula penal pelo juiz em razão de excesso manifesto a ser verificado de acordo com a natureza e o fim do negócio (segunda parte do artigo 413 do Código Civil). A análise cuidadosa da previsão legal deve ser feita mesmo nos contratos civis, tendo em vista que a legislação civil já prevê muitas regras que visam à tutela da equidade dos contratos e a proteção de eventual contratante que se encontre em posição de vulnerabilidade em relação ao outro. A interferência no contrato pode representar modificação da alocação de riscos originariamente pretendida, privilegiando-se a liberdade de contratar e o pacta sunt servanda nas relações empresariais. 


\section{BIBLIOGRAFIA}

\section{Doutrina}

AXELROD, Robert, The evolution of cooperation, Revised edition, Cambridge, 2006.

ASCARELLI, Tullio, $O$ desenvolvimento histórico do Direito Comercial e o significado da unificação do direito privado, in Revista de Direito Mercantil, Industrial, Econômico e Financeiro, n. 114, ano XXXVII, abril-junho/1999, p. 237252.

AZEVEDO, Alvaro Villaça, Inexecução culposa e cláusula penal compensatória, in Revista dos Tribunais, vol. 791, set. 2001, p. 121.

BARASSI, Lodovico, La teoria generale delle obligazioni, $22^{\mathrm{a}}$ ed., vol. 3, Milano, Giuffre, 1948.

BARBOSA MOREIRA, José Carlos, A tutela especifica do credor nas obrigações negativas, in Temas de direito processual, 2a série, São Paulo, Saraiva, 1984.

BENJAMIN, Peter, Penalties, liquidated damages and penalty clauses in commercial contracts a comparative study of english and continental law, in International and Comparative Law Quarterly, London, Eastern Press, vol. 9, n. 4, outubro 1960, p. 600-627.

BERNSTEIN, Lisa, Opting out of the Legal System: Extralegal Contractual Relations in the Diamond Industry, in The Journal of Legal Studies, vol. 21, n. 1, jan 1992, p. 115-157.

BERNSTEIN, Lisa, Private Commercial Law in the Cotton Industry: Creating Cooperation through Rules, Norms, and Institutions, Chicago John M. Olin Law \& Rconomic Working Paper no. 133, 2nd series, University of Chicago. 
BEVILAQUA, Clovis, Código Civil dos Estados Unidos do Brasil comentado, vol. 4, $7^{\mathrm{a}}$ ed., Rio de Janeiro, Francisco Alves, 1946.

BOULOS, Daniel Martins, O novo regime jurídico da cláusula penal: ensaio acerca da interpretação do artigo 413 do Código Civil, Tese de Doutorado, Pontifícia Universidade Católica de São Paulo, Professora Orientadora Rosa Maria de Andrade Nery, São Paulo, 2013.

CARLUCCI, Aída Kemelmajer de, La Cláusula penal, Buenos Aires, Depalma, 1981.

CARVALHO DE MENDONÇA, Manoel Inácio, Doutrina e prática das obrigações,

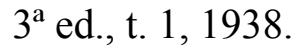

CAVAlIERI FILHO, Sergio, Programa de Responsabilidade Civil, 10 a ed., São Paulo, Atlas, 2012.

CLARKSON, Kenneth W.; MILLER, Roger Leroy, MURIS, Timothy J., Liquidated Damages v. Penalties: Sense Nonsense?, 1978, Wisconsin Law Review, 351, 356, 1978.

COASE, Ronald H., The nature of the firm, in Economica, New Series, vol. 4, ed. 16, November 1937, p. 386-405.

COASE, Ronald H., Economics and Contiguous Disciplines, in Richard A. Posner and Francesco Parisi, Law and Economics, vol. 1, 1997, p. 201-211.

COLUCCI, Joana, Preço alto de milho do Brasil faz trading cancelar contratos de exportação, Jornal Zero Hora, Porto Alegre, 21/06/2016, disponível em https://gauchazh.clicrbs.com.br/economia/campo-e-lavoura/noticia/2016/06/precoalto-do-milho-no-brasil-faz-trading-cancelar-contratos-de-exportacao-6099725.html (acesso em 12/12/2017).

CONTINENTINO, Múcio, Da Cláusula Penal no Direito Brasileiro, São Paulo, Livraria Acadêmica Saraiva e Companhia, 1926. 
COUTO E SILVA, Clovis V., A obrigação como processo, Rio de Janeiro, FGC, 2007.

DE MATTIA, Fábio Maria, Cláusula penal pura e cláusula penal não-pura, in Revista dos Tribunais, vol. 2, p. 1117, junho 2011.

DEMOGUE, René, Traité des obligations en general, vol. 6, Paris, Rousseau, 1931.

EISENBERG, Melvin A., Remedial Theory in Contract Law: compensation; the theory of efficient breach; cover; actual and virtual specific performance; and disgorgement, UC Berkeley Law and Economics Workshop, title: The Theory of Efficient Breach and the Theory of Efficient Termination, 19.04.2004.

EISENBERG, Melvin A., Why there is no law of relational contracts, in Northwestern University Law Review, vol. 94, n. 3, 2000, p. 805-822

FELÍCIO DOS SANTOS, Joaquim, Projeto do Código Civil da República dos Estados Unidos do Brazil, Rio de Janeiro, 1891.

FERNANDES, Wanderley, Cláusula de exoneração e limitação de responsabilidade, São Paulo, Saraiva, 2013.

FERNANDES, Wanderley (coord.), Contratos Empresariais - Fundamentos $e$ Princípios dos Contratos Empresariais, São Paulo, Saraiva, 2007 (série GV Law).

FERREIRA DA SILVA, Jorge Cesa, Inadimplemento das obrigações: mora, perdas e danos, juros legais, cláusula penal, arras ou sinal, coord. Miguel Reale e Judith Martins-Costa, São Paulo, RT, 2007.

FERRIANI, Carlos Alberto, Da clausula penal, in Revista de Direito Bancário e do Mercado de Capitais, vol. 55, p. 133, janeiro 2012. 
FORGIONI, Paula A., Apontamentos sobre algumas regras de interpretação dos contratos comericiais: Pothier, Cairu e Código Comercial 1850, in Revista de Direito Mercantil Industrial, Econômico e Financeiro, v. 141, p. 31-59, 2007.

FORGIONI, Paula A., Contratos empresariais. Teoria geral e aplicação. $2^{\mathrm{a}}$ ed. rev., atualiz. e ampl., São Paulo, Revista dos Tribunais, 2016.

FRANÇA, Rubens Limongi, Teoria e prática da cláusula penal, São Paulo, Saraiva, 1988.

FRANCO, Vera Helena de Mello, Os contratos empresariais e seu tratamento após o advento do Código Civil de 2002, in Revista de Direito Mercantil, Industrial, Econômico e Financeiro, n. 151/152, Jan/Dez/2009, pp. 22-46.

FREITAS, Teixeira, Consolidação das Leis Civis, Rio de Janeiro, Typographia Universal de Laemmert, 1987.

GALGANO, Francesco, "Lex mercatoria”, traduzido por Erasmo Valladão A. e N. França, in Revista de Direito Mercantil, Industrial, Econômico e Financeiro, n. 129, ano XLII, janeiro-março/2003, p. 224-228.

GOETZ, Charles J.; SCOTT, Robert E., Liquidated damages, penalties and the just compensation principle: some notes on an enforcement model and a theory of efficient breach, in Columbia Law Review, n. 77, 1977.

GOMES, Orlando, Obrigações, $17^{\mathrm{a}}$ ed., atualiz. por Evaldo Brito, Rio de Janeiro, Forense, 2008.

HATZIS, Aristides N., Having the cake and eating it too: efficient penalty clauses in Common and Civil contract law, in International Review of Law and Economics, 22, 2003, p. 381-406. 
HESSELINK, Martijn, Towards a sharp distinction between B2B and B2C? On consumer, commercial and general contract law after the consumer rights directive, in Centre for the Study of European Contract Law, Working Paper Series n. 2009/06.

JUNQUEIRA DE AZEVEDO, Antonio, Novos Estudos e Pareceres de Direito Privado, São Paulo, Saraiva, 2009.

LEÃES, Luiz Gastão Paes de Barros, Inexistência de relação de consume entre o shopping center e seus frequentadores, in Pareceres, vol. II, São Paulo, Singular, 2004.

MACEDO, Ronaldo Porto, Contratos Relacionais e Defesa do Consumidor, $2^{\mathrm{a}}$ ed., rev., atualiz. e ampliada, São Paulo, Revista dos Tribunais, 2007.

MACNEIL, Ian, Efficient breach of contract: circles in the sky, in Virginia Law Review, vol. 68, n. 5, maio 1982, p. 947-969.

MARQUES, Claudia Lima, Contratos no Código de Defesa do Consumidor, $4^{\mathrm{a}}$ ed., São Paulo, RT, 2002.

MARTINS, Camila Rezende, $O$ principio da relatividade dos contratos e a responsabilidade do terceiro que contribui para o inadimplemento contratual, Dissertação de Mestrado, Universidade de São Paulo, Orientadores Antonio Junqueira de Azevedo e Alcides Tomasetti Junior, São Paulo, 2011.

MARTINS-COSTA, Judith, Comentários ao Novo Código Civil, coord. Sálvio de Figueiredo Teixeira, vol. 5, t. II, Rio de Janeiro, Forense, 2004.

MARTINS-COSTA, Judith, A Boa-fé no Direito Privado: critérios para a sua aplicação, São Paulo, Marcial Pons, 2015.

MAZEAUD, Denis, La notion de clause pénale, Paris, LGDJ, 1992. 
MÉNARD, Claude, The Economics of Hybrid Organizations, in Journal of Institutional and Theoretical Economics, 2004, p. 345-376.

MOREIRA ALVES, José Carlos, A Unificação do Direito Privado Brasileiro - de Teixeira de Freitas ao Novo Código Civil, in Princípios do Novo Código Civil Brasileiro e outros temas em homenagem a Tullio Ascarelli, coord. Antonio Junqueira de Azevedo, Heleno Tavares Torres e Paolo Carbone, São Paulo, Quartier Latin, 2008, p. 363-385

NERY JUNIOR, Nelson e NERY, Rosa Marian de Andrade, Código Civil comentado,

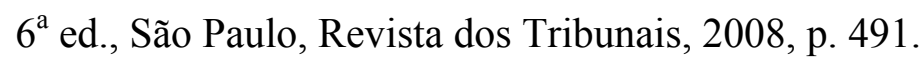

PELA, Juliana Krueger, "Inadimplemento eficiente” (efficient breach) nos contratos empresariais, in Revista Jurídica Luso Brasileira, Ano 2, n. 1, 2016, p. 1091-1103.

PELA, Juliana Krueger, Rembrandt e o direito privado, Revista da Faculade de Direito da Universidade de São Paulo, v. 110, jan/dez 2015, p. 319-327.

PELA, Juliana Krueger, Risco e contratos empresariais - A aplicação da resolução por onerosidade excessiva, in Direito Empresarial - Estudos em homenagem ao Professor Haroldo Malheiros Duclerc Verçosa, vol. 1, $1^{\text {a }}$ ed., São Paulo, IASP, 2015, p. 487-498.

PEREIRA, Caio Mario da Silva, Instituições de direito civil, vol. 2, 17 a ed., Rio de Janeiro, Forense, 1999.

PINTO MONTEIRO, Antônio, Cláusula penal e imndenização, Coimbra, Almedina, 1990.

PINTO MONTEIRO, Antonio, Cláusulas limitativas e de exclusão de responsabilidade civil, $2^{\mathrm{a}}$ ed., Coimbra, Almedina, 2011.

PINTO MONTEIRO, Antonio, Responsabilidade Contratual: Cláusula penal e comportamento abusivo do credor, texto que reproduz a intervenção oral gravada e 
depois revisto pelo autor, XXII Congresso Internacional de Direito Comparado, realizado na EMERJ em 05.09.2003, em Revista da EMERJ, v. 7, n. 26, 2004.

PONTES DE MIRANDA, Francisco Cavalcanti, Tratado de Direito Privado, tomos III, XXVI, LIV, 4a ed., São Paulo, Revista dos Tribunais, 1983-84.

POSNER, Richard A.; PARISI, Francesco, Law and Economics, v. 1, 1997, p. ixxlviii (introduction).

POSNER, Richard A., Let us never blame a contract breaker, in Michigan Law Review, vol. 107, n. 8, Junho 2009, p. 1349-1363.

PRESSMAN, Michael, The two-contract approach to liquidated damages: a new framework for exploring the penalty clause, in Virginia Law \& Business Review, vol. 7, n. 4, p. 651-708, spring 2013.

RICARDO E SERPA, Pedro, Indenização Punitiva, Dissertação de Mestrado, Faculdade de Direito da Universidade de São Paulo, Orientadores: Prof. Titular Antonio Junqueira de Azevedo e Alcides Tomasetti Jr., 2011.

RODRIGUES JUNIOR, Otavio Luiz, Função, Natureza e Modificação da Cláusula Penal no Direito Civil Brasileiro, Tese de Doutorado, Faculdade de Direito da Universidade de São Paulo, Professor Orientador Antonio Junqueira de Azevedo, São Paulo, 2006.

RODRIGUES, Silvio, Direito Civil - parte geral das obrigações, vol. 2, 4ª ed., São Paulo, Saraiva, p. 81.

ROPPO, Enzo, O contrato, trad. Ana Coimbra e M. Januário C. Gomes, Coimbra, Almedina, 2009.

SALAMA, Bruno M., Direito e Economia, in José R. Rodriguez, Fragmentos para um Dicionário Crítico de Direito e Desenvolvimento, São Paulo, Saraiva, 2011. 
SALAMA, Bruno M., O que é pesquisa em direito e economia?, Cadernos Direito GV, vol. 5, n. 2, 2008.

SALOMÃO FILHO, Calixto, Regulação e atividade econômica (princípios e fundamentos jurídicos), $2^{\mathrm{a}}$ ed., São Paulo, Malheiros, 2008.

SCALISE JR., Ronald, Why no efficient breach in civil law? A comparative assessment of the doctrine of efficient breach in contract, in The American Journal of Comparative Law, vol. 55, n. 4, 2007, p. 721-766.

SCHAFER, Hans-Bernd; OTT, Claus, Manual de Análisis Economico Del Derecho Civil, trad. Mararena Von Carstenn-Lichterfelde, Madrid, Tecnos, 1991.

SERPA LOPES, Miguel Maria de, Curso de Direito Civil, $7^{\mathrm{a}}$ ed., Rio de Janeiro, Freitas Bastos, vol. 2, 2000.

SZTAJN, Rachel, Sociedades e Contratos Incompletos, in Revista da Faculdade de Direito da Universidade de São Paulo, v. 101, jan/dez 2006.

SERPA LOPES, Miguel Maria, Curso de Direito Civil, vol. II, $6^{\text {a }}$ ed. rev. e atualz. por José Serpa Santa Maria, Rio de Janeiro, Freitas Bastos, 1995.

TIMM, Luciano, Direito e Economia, Porto Alegre, IOB-Thomson, 2005.

XIMENES, Julia Maurmann, O processo de produção científico jurídica - $O$ problema é o problema, Anais do XVII Congresso Nacional do COPENDI, Florianópolis, Fundação Boiteux, 2008, p. 4791-4805.

ZYLBERSZTAJN, Décio; SZTAJN, Rachel, Direito \& Economia: análise econômica do direito e das organizações, Rio de Janeiro, Elsevier, 2005.

\section{Jurisprudência ${ }^{235}$}

${ }^{235}$ Os julgados utilizados como bibliografia foram listados por corte, em ordem cronológica. 
TJSP, Agravos de Instrumento n. ${ }^{\circ} 346.328 .4-5$ e 346.344.4-8, Rel. Des. Roberto Mortari, j. 31.04.2004.

TJSP, Apelação n. ${ }^{0}$ 7.155.293-9, Rel. Des. Pedro Alexandrino Ablas, j. 09.04.2008.

STJ, Recurso Especial n. ${ }^{\circ}$ 965.500-ES, Rel. Min. José Delgado, Primeira Turma, j. 18.12.2007.

STJ, Recurso Especial n. ${ }^{\circ}$ 763.531-RJ, Rel. Carlos Fernando Mathias, Segunda Turma, j. 25.03.2008

STJ, Recurso Especial n. ${ }^{\text {9 } 910.794-R J, ~ R e l . ~ M i n . ~ D e n i s e ~ A r r u d a, ~ P r i m e i r a ~ T u r m a, ~ j . ~}$ 21.10.2008.

STJ, Embargos de Divergência em REsp n. ${ }^{\circ} 748.868-R S$, Rel. Min. Humberto Martins, Primeira Seção, j. 25.03.2009

STJ, AgRg no Agravo de Instrumento 1.075.691/SP, Rel. Min. Maria Isabel Gallotti, Quarta Turma, j. 23.08.2011

STJ, AgRg no Agravo em Recurso Especial n. ${ }^{\circ}$ 18.180-RJ, Rel. Min, Herman Benjamin, Segunda Turma, j. 20.09.2011

STJ, Recurso Especial n. ${ }^{\circ}$ 1.212.159/SP, Rel. Min. Paulo de Tarso Sanseverino, Terceira Turma, 19.06.2012.

STJ, Recurso Especial n. ${ }^{\circ}$ 932.557, Rel. Min. Luis Felipe Salomão, j. em 07.02.2012.

STJ, AgRg no Recurso Especial n. ${ }^{\circ}$ 977.219-SP, Rel. Min. Ricardo Villas Bôas Cueva, Terceira Turma, j. 01.03.2012 
STJ, AgRg no Agravo em Recurso Especial n. ${ }^{\circ}$ 132.553-RS, Rel. Min. Castro Meira, Segunda Turma, 10.04.2012

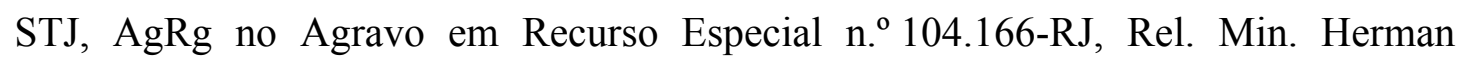
Benjamin, Segunda Turma, j. 24.04.2012

STJ, Recurso Especial n. ${ }^{\text {8 }}$ 839.923-MG, Rel. Min. Raul Araújo, Quarta Turma, j. 15.05 .2012

STJ, Recurso Especial n. ${ }^{\circ}$ 1.300.187-MS, Rel. Min. Raúl Araújo, Quarta Turma, j. 17.05.2012

STJ, AgRg no Agravo em Recurso Especial n. ${ }^{\circ}$ 178.255- SE, Rel. Min. Castro Meira, Segunda Turma, j. 18.04.2013

STJ, AgRg no Recurso Especial n. ${ }^{\circ}$ 1.243.202-RS, Rel. Min. Raúl Araújo, Quarta Turma, j. 16.05.2013

STJ, AgRg no Recurso Especial n. ${ }^{\circ}$ 1.209.123-SP, Rel. Min. Luis Felipe Salomão, Quarta Turma, j. 18.02.2014

STJ, Recurso Especial n. ${ }^{o}$ 1.186.789/RJ, Rel. Min. Luis Felipe Salomão, Quarta Turma, j. 20.03.2014.

STJ, Recurso Especial n. ${ }^{\circ}$ 1.354.536-SE, Rel. Min. Luis Felipe Salomão, Segunda Seção, j. 26.03.2014

STJ, AgRg no Agravo em Recurso Especial n. ${ }^{\circ}$ 485.051-PR, Rel. Min. Herman Benjamin, Segunda Turma, j. 13.05.2014

STJ, Recurso Especial n. ${ }^{\circ}$ 1.203.153/SP, Rel. Min. Paulo de Tarso Sanseverino, j. 03.06 .2014 . 
STJ, Recurso Especial nº. 963.852/PR, Rel. Min. Antônio Carlos Ferreira, j. em 19.08.2014.

STJ, AgRg no Agravo em Recurso Especial n. ${ }^{\circ}$ 607.167-SP, Rel. Min. Raúl Araújo, Quarta Turma, j. 18.09.2014

STJ, Recurso Especial n. ${ }^{\circ}$ 1.280.372, Rel. Min. Ricardo Villas Bôas Cueva, j. em 07.10.2014.

STJ, AgRg no Agravo em REsp 592.075/RJ, Rel. Min. João Otávio de Noronha, Terceira Turma, j. 05.03.2015.

STJ, EDCl no AgRg no Agravo em Recurso Especial n. ${ }^{\circ}$ 540.533-PR, Rel. Min. Moura Ribeiro, j. 03.03.2015

STJ, AgRg no Agravo em Recurso Especial n. ${ }^{o}$ 633.251-SP, Rel. Min. Raúl Araújo, Quarta Turma, j. 05.05.2015

STJ, Recurso Especial n. ${ }^{\circ}$ 1.520.820-SE, Rel. Min. Herman Benjamin, Segunda Turma, j. 16.06.2015

STJ, AgRg no Agravo em REsp n. ${ }^{\circ}$ 44.210/SP, Rel. Min. Maria Isabel Gallotti, Quarta Turma, j. 22.09.2015.

STJ, AgRg no Agravo em Recurso Especial n. ${ }^{\circ}$ 712.010-RJ, Rel. Min. Herman Benjamin, Segunda Turma, j. 01.10.2015

STJ, Recurso Especial n. ${ }^{\circ}$ 1.424.074/SP, Rel. Min. Ricardo Villas Bôas Cueva, Terceira Turma, j. 10.11.2015.

STJ, AgRg nos EREsp n. ${ }^{\circ}$ 1.331.112, Corte Especial, rel. Min. Herman Benjamin, j. em 03.12.2015. 
STJ, AgRg no Recurso Especial n. ${ }^{\circ}$ 1.348.883-RJ, Rel. Min. Regina Helena Costa, Primeira Turma, j. 03.03.2016

STJ, AgRg no Recurso Especial n. ${ }^{\circ}$ 1.244.153-RS, Rel. Min. Assusete Magalhães, j. 07.04 .2016

STJ, Recurso Especial n. ${ }^{\circ}$ 1.457.234-PB, Rel. Min. João Otávio de Noronha, Terceira Turma, j. 15.09.2016

STJ, AgRg no Agravo em Recurso Especial n. ${ }^{\circ}$ 466.168-RN, Rel. Des. Olindo Menezes, Primeira Turma, j. 27.10.2016.

STJ, AgInt na Reclamação n. ${ }^{0}$ 9.932-SP, Rel. Min. Raúl Araújo, Presidente Min. Paulo de Tarso Sanseverino, Segunda Seção, j. 23.11.2016.

STJ, AgInt no Recurso Especial n. ${ }^{\circ}$ 1.455.472-SC, Rel. Min. Assusete Magalhães, Segunda Turma, j. 04.04.2017

STJ, Recurso Especial n. ${ }^{\circ}$ 1.645.744-SP, Rel. Min. Ricardo Villas Bôas Cueva, Terceira Turma, j. 06.06.2017

STJ, Recurso Especial n. ${ }^{\circ}$ 1.680.689-RJ, Rel. Min. Herman Benjamin, Segunda Turma, j. 21.09.2017

STJ, AgInt no Agravo em Recurso Especial n. ${ }^{\circ}$ 1.067.993-RO, Rel. Min. Marco Aurélio Belizze, Terceira Turma, j. 09.11.2017 